\title{
Necropsy findings in neonatal asphyxiating thoracic dystrophy
}

\author{
SUSAN BECKWITT TURKEL* , EVELYN J DIEHL*§, \\ AND JOHN A RICHMOND †
}

From the Departments of Pathology* and Radiologyt, University of Southern California School of Medicine; Los Angeles County-USC Medical Center $\ddagger$, and Children’s Hospital of Los Angeles\$, Los Angeles, California, USA.

SUMMARY Asphyxiating thoracic dystrophy is an autosomal recessive disorder characterised by an abnormally small thorax, variable shortening of the extremities, and pelvic anomalies. Renal $\vec{N}$ and pancreatic symptoms are found in longer survivors, although most cases die in infancy of 의 respiratory failure. Seven neonatal cases were studied at necropsy. These cases ranged in $\rightarrow$ gestational age from 32 to 40 weeks. One was stillborn and the other six survived from 1 hour to $\frac{7}{2}$ 10 days. Two were sibs born to consanguineous parents. Dwarfing was not pronounced and the extremities were shortened in only one infant who also had polydactyly. All seven showed $\vec{\oplus}$ visceral changes in addition to abnormalities of bone. Endochondral ossification was irregular in or sections of femur, vertebra, and rib. Pulmonary hypoplasia was associated with the small thorax typical of this disorder. Periportal fibrosis and bile duct proliferation were seen in sections of liver, and in one case cirrhosis was found. Pancreatic fibrosis was variable. These necropsy findings correlate with later clinical manifestations of the disease and emphasise the multisystem $\stackrel{\mathscr{D}}{\varnothing}$ nature of this disorder.

In 1955 Jeune and his co-workers described two sibs with what they termed 'dystrophie thoracique asphyxiante de caractère familial', or asphyxiating thoracic dystrophy. ${ }^{12}$ Since that time there have been approximately 100 more cases reported, predominantly in European and radiological publications. ${ }^{34}$ The diagnosis is usually confirmed by radiological demonstration of typical skeletal abnormalities, which include the characteristically small thorax, varying degrees of shortening of the extremities, polydactyly, and pelvic abnormalities. These features have led to the alternate designation of the syndrome as thoracic-pelvic-phalangeal dystrophy. ${ }^{5}$ Pulmonary hypoplasia and respiratory distress secondary to the small thorax usually lead to early death, although some patients may survive the newborn period. Variable skeletal abnormalities and pancreatic and renal insufficiency are found in longer survivors, and most have portal abnormalities on liver biopsy or at necropsy, although hepatic symptoms are very rare.

We report the necropsy findings in seven newborn

Received for publication 25 January 1984

Accepted for publication 11 July 1984 infants with Jeune's asphyxiating thoracic dysplasia (JATD), which emphasise the systemic nature of this autosomal recessive disorder at birth.

\section{Materials and methods}

The necropsy findings in seven cases of Jeune's asphyxiating thoracic dysplasia, five from Los 음 Angeles County-University of Southern California $>$ Medical Center and two from the Children's Hospital of Los Angeles, were reviewed. All seven infants died in the perinatal period (table 1). One female infant was stillborn at 36 weeks' gestation and the $N$ other six were liveborn between 32 and 40 weeks' N్ gestation, surviving from 1 hour to 10 days. Four of 0 the liveborns died almost immediately of respiratory failure, the fifth of sepsis at 2 days, and the sixth $\frac{}{\Phi}$ succumbing to respiratory and cardiac failure owing $\stackrel{\oplus}{+}$ to tetralogy of Fallot at 10 days. There were four 7 females and three males. The demographic distribu- ${ }_{\vec{O}}$ tion was typical for our patient population, with one $\stackrel{\mathbb{Q}}{\mathbb{Q}}$ Caucasian, one Negro, and five Latino babies. Two $\underset{\mathbb{Q}}{\mathbb{Q}}$ were sibs born to consanguineous parents (fig 1). In one case the mother is again pregnant and may be 
TABLE 1 Clinical data.

\begin{tabular}{|c|c|c|c|c|c|c|c|}
\hline & $\begin{array}{l}\text { Case } \\
1\end{array}$ & 2 & 3 & 4 & 5 & 6 & 7 \\
\hline \multirow{6}{*}{$\begin{array}{l}\text { Sex } \\
\text { Race } \\
\text { EGA (wk) } \\
\text { Age } \\
\text { Other }\end{array}$} & $\mathrm{F}$ & $\mathbf{M}$ & \multirow{6}{*}{$\begin{array}{l}\text { F } \\
\text { Latino } \\
32 \\
2 \mathrm{~h} \\
\text { Cleft }\end{array}$} & \multirow{6}{*}{$\begin{array}{l}\mathrm{M} \\
\text { Latino } \\
40 \\
1 \mathrm{~h} \\
6 \text { digits }\end{array}$} & $\mathrm{F}$ & \multirow{6}{*}{$\begin{array}{l}\mathrm{M} \\
\text { Caucasian } \\
38 \\
10 \mathrm{~d} \\
\mathrm{~T} / \mathrm{F}\end{array}$} & \multirow{6}{*}{$\begin{array}{l}\text { F } \\
\text { Latino } \\
40 \\
5 \mathrm{~h} \\
\text { Cirrhosis }\end{array}$} \\
\hline & Latino & Latino & & & Negro & & \\
\hline & 36 & 40 & & & 36 & & \\
\hline & SB & $2 \mathrm{~h}$ & & & $2 \mathrm{~d}$ & & \\
\hline & & & & & & & \\
\hline & \multicolumn{2}{|c|}{ Sibs } & & & & & \\
\hline
\end{tabular}

carrying an affected fetus, based on ultrasound examination (fig 2). The other five cases had neither affected sibs nor contributory family history. All seven infants showed the characteristic skeletal abnormalities of neonatal JATD, with extremely narrowed and shortened thoraces. The extremities were only mildly shortened in six cases, but markedly so in the seventh, who was also the only infant with polydactyly. One infant had a cleft palate and she and one other had prominent frenula connecting the tongue to the midline gingiva. ${ }^{4}$ Radiological examination confirmed the diagnosis of JATD (fig $3)$. Comparison of the necropsy findings in these seven cases was undertaken.

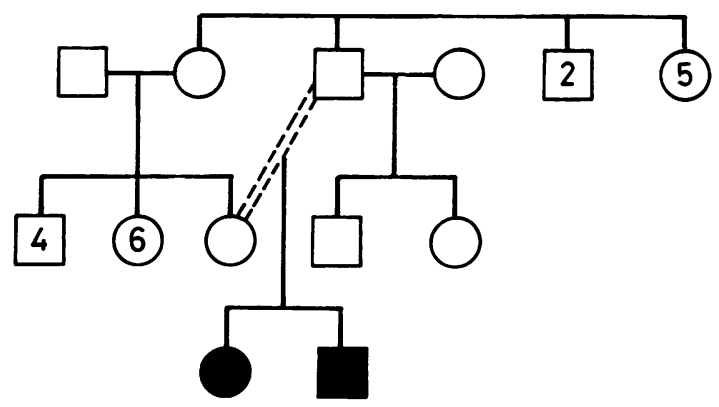

FIG 1 Pedigree of cases 1 and 2.

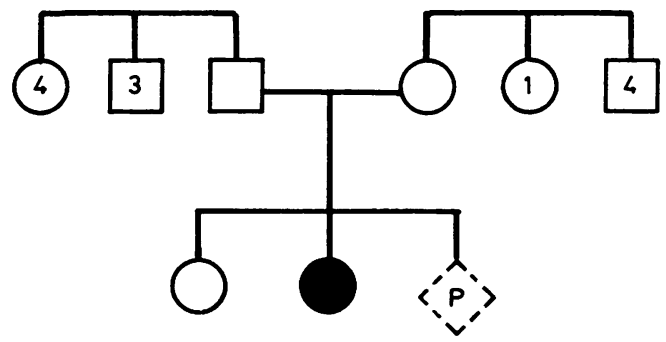

FIG 2 Pedigree of case 5.

\section{Results}

Changes in the bone varied among patients and between sites. Rib sections were examined in five cases. All showed dense, sclerotic bone with abnormally thick trabeculae, and lacked a distinct epiphyseal growth plate or costochondral junction. In only one case could chondrocyte columnisation be appreciated, and in this case it was severely deranged (fig 4). Vertebral sections were examined in five cases. All showed thicker than normal bony trabeculae and four showed an irregular scalloped margin to the zone of the endochondral ossification. Irregular and disarrayed chondrocyte columns were found in three cases. One case showed focal myxoid change of the cartilage, and scattered small calcific concretions were seen in one other. Sections of femur were examined from three cases and slightly different changes were seen in each. In one, relatively orderly but abbreviated chondrocyte columns were found, resulting in thin and delicate bony trabeculae. In the other two cases, the bony trabeculae were abnormally thickened. In one of these the growth plate and chondrocyte columnisation were only mildly irregular. In the infant with polydactyly and the most severe dwarfing of the extremities, the femoral growth plate was the most abnormal, with markedly irregular columnisation and deranged and disorderly trabecular formation (fig 5).

The lungs appeared small and atelectatic in all seven cases, their configuration conforming to the small, narrow thoracic cavity. By weight the lungs were smaller than expected (table 2). Two showed microscopic evidence of hypoplasia, with small cartilagenous bronchi extending near the pleura. ${ }^{7}$

The livers were not enlarged, except in one instance, and did not feel unusually firm. Microscopic abnormalities were found in the liver in all the cases. These were typified by moderate to marked expansion of the portal areas with proliferation of the intermediate and Hering ducts (fig 6). There was increased periportal fibrous tissue, and bridging with early cirrhosis was found in one case. 




(a)

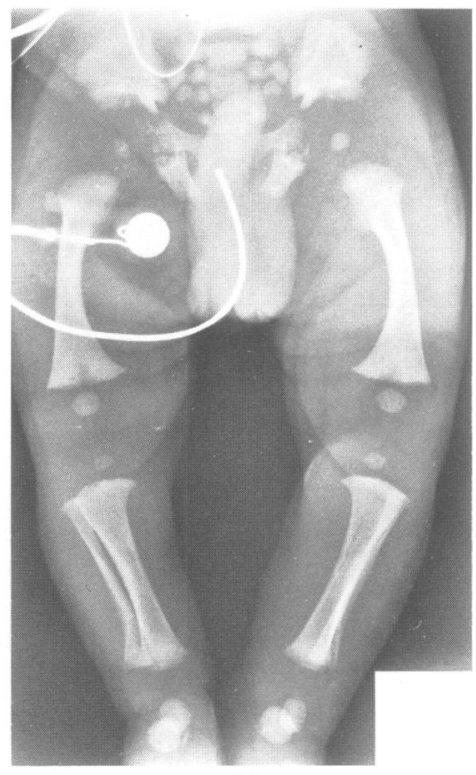

(b)

FIG 3 Radiographs of case 2, illustrating typical changes seen at term. (a) Note the symmetrically short ribs, resulting in a small, rectangular shaped thorax.

(b) Note the small ilia with medial bony projections and lateral flattening and irregularity of the lower margins. There is premature ossification of the capital femoral epiphyses. The long bones appear mildly shortened.

The portal changes were seen in all the cases, and could even be appreciated in the autolytic liver of the stillborn. Vacuolation of hepatocellular cytoplasm was observed in three cases. Mildly to moderately increased iron in hepatocytes, confirmed by iron stain, was found in a predominantly periportal distribution in all cases, and a trace of periportal hepatocellular iron could be detected in the autolytic liver of the stillborn.

To a varying degree, microscopic cystic changes were seen in the kidneys in all seven cases, although grossly visible cysts were not observed. These cysts appeared to arise from dilation of the collecting ducts, and were not associated with any inflammation, tubular or glomerular atrophy, or interstitial fibrosis (fig 7). Mild cystic changes were found in three cases and more numerous small cysts in the remainder.

Pancreatic abnormalities were found in five of the six cases in whom fixation permitted histological evaluation. One case showed marked interstitial fibrosis and an associated inflammatory infiltrate

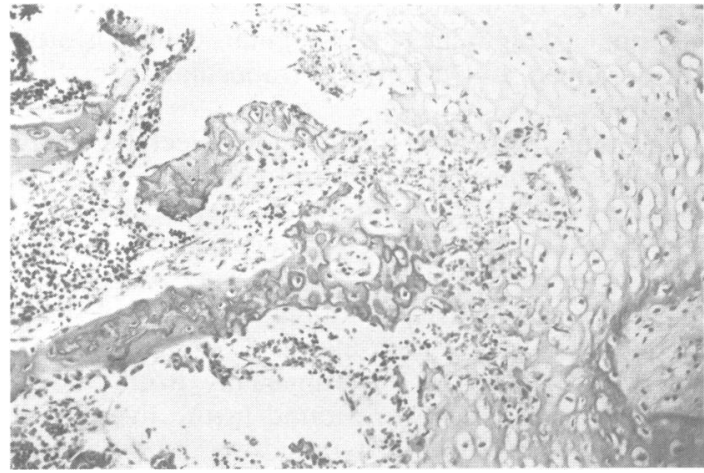

FIG 4 Section of rib taken from case 2. Chondrocyte columnisation is disrupted and the bony trabeculae formed are abnormal. (Haemotoxylin and eosin. Original magnification $\times 40$.)

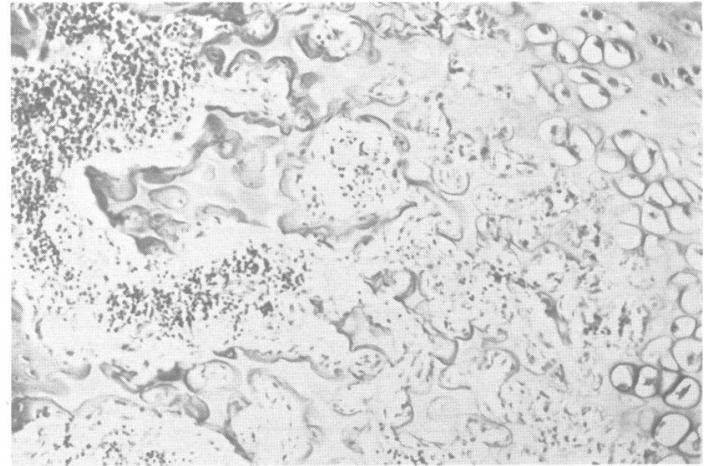

FIG 5 In this section of femur taken from case 4 the growth plate is abnormal, with irregular chondrocyte columns, vascular ingrowth, and trabecular formation. (Haemotoxylin and eosin. Original magnification $\times 40$.) 
TABLE 2 Necropsy data.

\begin{tabular}{|c|c|c|c|c|c|c|c|}
\hline & $\begin{array}{l}\text { Case } \\
1\end{array}$ & 2 & 3 & 4 & 5 & 6 & 7 \\
\hline Weight $(\mathrm{g})$ & 2210 & 3680 & 1610 & 2000 & 3340 & & 4260 \\
\hline Crown:rump $(\mathrm{cm})$ & 33 & 34 & 28 & 29 & 37 & & 38 \\
\hline Crown:heel $(\mathrm{cm})$ & 44 & 49 & 38 & 40 & 48 & 46 & 48 \\
\hline Chest $(\mathrm{cm})$ & & 29 & 21 & 22 & 28 & 26 & 31 \\
\hline Liver (g) & 54 & 180 & 64 & 75 & 139 & 110 & 278 \\
\hline Expected $^{46}$ & 98 & 178 & 76 & 76 & 155 & & 215 \\
\hline Lungs $(\mathrm{g})$ & 19 & 26 & 9 & 10 & 28 & 70 & 13 \\
\hline Expected $^{46}$ & 44 & 58 & 37 & 37 & 55 & & 66 \\
\hline
\end{tabular}

consisting of numerous lymphocytes, polymorphonucleocytes, eosinophils, plasma cells, and macrophages. Polymorphonucleocytes were also seen within the lumina of dilated pancreatic ducts in this case. The other three cases showed very mildly

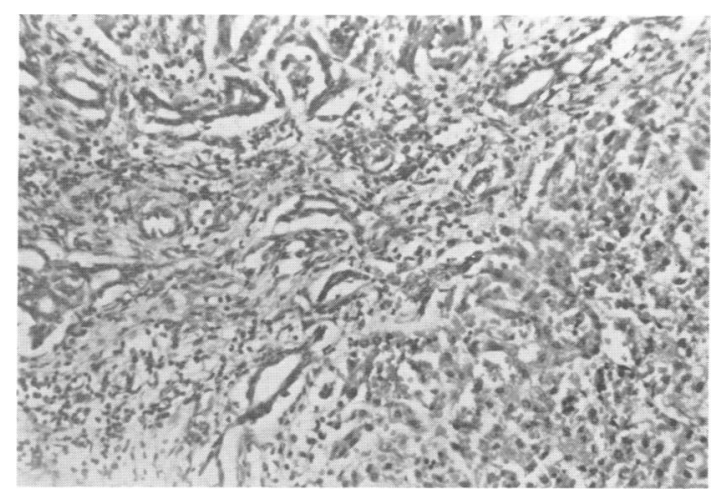

FIG 6 Pronounced bile duct proliferation and associated periportal fibrosis can be seen in this section of liver taken from case 7. (Haemotoxylin and eosin. Original magnification $\times 40$.)

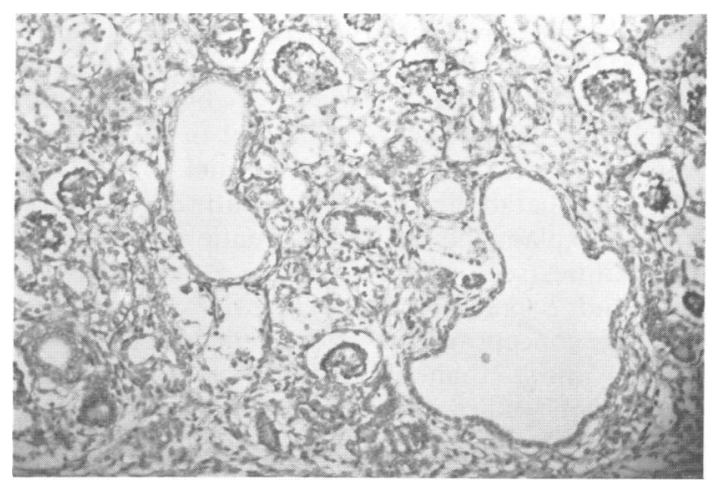

FIG 7 Ectatic collecting ducts are apparent in this section of kidney taken from case 3. (Periodic acid-Schiff. Original magnification $\times 40$.) increased trabecular connective tissue and minimally dilated ducts, most apparent in the head of the pancreas. The pancreas in the last case was unremarkable.

With the exception of the one case with congenital heart disease, the internal organs appeared grossly normal at necropsy, and microscopic examination of the viscera showed no additional changes.

\section{Discussion}

Jeune's asphyxiating thoracic dystrophy is a rare autosomal recessive disorder with varying clinical manifestations. It is characterised by an abnormally small thorax which results from severe abnormalities of the ribs, and this has remained its most outstanding diagnostic criterion. The thoracic malformation usually leads to pulmonary hypoplasia and respiratory insufficiency, and patients with this disorder often die in infancy, rarely surviving longer than 2 years. ${ }^{34}$ Polydactyly, ${ }^{34}$ 8-11 $^{11}$ cleft lip and palate, ${ }^{11}$ abnormal teeth, ${ }^{312}$ and variable degrees of limb shortening ${ }^{5}$ are sometimes noted. In longer survivors, skeletal and systemic symptoms are more variable. ${ }^{1314}$ Dwarfing may be minimal or severe, and hepatic, renal, and pancreatic dysfunction are reported.

Radiological examination is essential in classifying the various forms of neonatal dwarfism. With JATD, the ribs are short and all approximately the same length, producing a small rectangular shaped thorax (fig 4). The ilia of the pelvis are small with irregular flattening and medial bony projections on the lower margins. ${ }^{56}$ The ossification pattern may be abnormal in patients with JATD, and premature ossification of the capital femoral epiphyses is typically seen in the newborn period. ${ }^{15}$

Previous reports of the morphology of the epiphyseal growth plate in JATD have described findings similar to those found in our cases. The ribs are usually the most severely affected, with failure of endochondral ossification and markedly deficient and irregular chondrocyte columns. ${ }^{11}{ }^{16-22}$ Usually the rib changes are more severe than those in the 
vertebrae and long bones, ${ }^{16} 21$ and femoral and vertebral findings are more variable. This seems consistent with the variable degree of truncal and limb dwarfing seen with this disorder. Histologically, disorganisation of the growth plate with irregular chondrocyte columns and metaphyseal cartilage islands in some patients ${ }^{11} 192324$ to microscopically normal bone in others ${ }^{15}$ have been described. Ultrastructural studies of the costochondral junction from patients with JATD have demonstrated intracytoplasmic lipid droplets within chondrocytes. ${ }^{25}$

Previous morphological studies of the lungs of necropsied cases of JATD have documented pulmonary hypoplasia by small lung weight ${ }^{16}$ and microscopic evidence of parenchymal developmental insufficiency. ${ }^{7}$ Pneumonia ${ }^{21} 2226$ and pulmonary haemorrhage ${ }^{21}$ are also reported at necropsy. Although histological corroboration of pulmonary hypoplasia could be established in only two of our cases, in all the lungs were small. Five of the six liveborn infants in our series died soon after birth of respiratory failure, in one case complicated by sepsis. These histories are typical of this disorder, where the majority of patients soon die of respiratory failure, many in the first few days. ${ }^{34}$

Heart disease is less often recognised in patients with JATD, but pulmonary hypertension and cor pulmonale may be late complications of long standing pulmonary obstruction. ${ }^{27}$ Right ventricular hypertrophy, ${ }^{18}$ congestive heart failure, ${ }^{51028}$ murmurs, ${ }^{29}$ and subendocardial fibroelastosis ${ }^{19}$ have been reported. Congenital heart defects are uncommon. ${ }^{3}$

Portal fibrosis and bile duct proliferation have been occasionally described in previous necropsy reports of patients with JATD. ${ }^{18} 2122{ }^{30}$ Hepatic symptoms are usually not a feature of this disorder and jaundice is rare. ${ }^{2831}$ The hepatic lesion of JATD is characterised by proliferation of predominantly intermediate bile ducts with some fibrosis around the intralobular Hering ducts. ${ }^{30}$ In addition to this, one of our cases had cirrhosis, which has not been previously reported in a neonate.

Chronic renal failure is the commonest cause of death in longer survivors with JATD.$^{5}{ }^{32}$ The renal findings in JATD are variable, ranging from normal kidneys, to mild cystic changes, to severe scarring and renal failure, which is more common in longer survivors. ${ }^{59}$ The late findings of interstitial and periglomerular fibrosis, round cell infiltration, tubular atrophy and dilation, and hyalinised glomeruli have been categorised as a form of interstitial nephritis or nephronophthisis. ${ }^{18}{ }^{33}$ The combination of cystic change in the kidney and bile duct proliferation in the liver is reminiscent of type III renal dysgenesis or infantile polycystic disease of kidneys and liver, ${ }^{22}{ }^{32}$ but the pattern of both portal and renal abnormalities can be distinguished between this and JATD. ${ }^{30}$

Cystic dilation of the collecting ducts is the most common change in the kidneys in newborns,${ }^{4}$ and this change was found to a varying degree in all our cases. We did not find inflammation, tubular atrophy, or hyalinised glomeruli, which are late changes ${ }^{32-34}$ infrequently seen in the neonate. ${ }^{24}$ Type IV renal dysgenesis, resulting from bilateral stenosis at the ureterovesicular junction, ${ }^{21}$ and bilateral hydronephrosis without obstruction ${ }^{35}$ have also been reported.

Pancreatic exocrine insufficiency is a rare complication seen in older patients with $\mathrm{JATD}^{35}$ and some previous studies have documented microscopic cystic change in the pancreatic ducts in longer survivors, ${ }^{23} 31$ although pancreatitis and fibrosis have not been described before in neonatal JATD.

JATD can be separated from other congenital disorders which are associated with small thoraces, limb dwarfing, and visceral abnormalities. Consideration of the clinical, radiological, and pathological features is necessary to separate JATD from similar disorders. Ellis-van Creveld disease ${ }^{36} 37$ and the Saldino-Noonan and Majewski types of short ribpolydactyly syndrome ${ }^{38}$ may also have renal, hepatic, and pancreatic changes at necropsy, in addition to small thorax, polydactyly, and pelvic abnormalities ${ }^{38-40}$ Associated cardiac, ectodermal, and internal malformations found with these syndromes allow them to be distinguished from JATD. ${ }^{23}$ Thanatophoric dwarfism, homozygous achondroplasia, camptomelic dwarfism, and achondrogenesis show much more severe limb dwarfing and the associated visceral changes again differ from those found with JATD. ${ }^{2.3}$

Other investigators have demonstrated that an autosomal recessive pattern of inheritance is likely for JATD. ${ }^{51621}$ Many reports describe affected sibs in the same family $92037.3941-43$ even without parental consanguinity, as we found in two of our seven cases. Karyotypes are normal. ${ }^{13} 2044$ An underlying metabolic defect is an attractive hypothesis to explain the multiple somatic and visceral abnormalities seen with this disorder, and hepatic, renal, and pancreatic involvement are consistent with the concept of an inborn metabolic error affecting more than just the skeleton. So far biochemical studies in patients with JATD have been unsuccessful in demonstrating a metabolic abnormality, ${ }^{45}$ but future study may eventually elucidate one.

The findings in our seven necropsy cases of neonatal JATD emphasise that this is a disorder 
affecting not only the skeletal system, but the internal organs as well. Although visceral changes may not be grossly or clinically apparent, they are histologically demonstrable at the time of birth. These findings in neonatal JATD are sufficiently characteristic to allow pathological diagnosis. It is important to identify this disorder properly and to distinguish it from other forms of potentially lethal neonatal dwarfism, so that appropriate family counselling and future histopathological and biochemical studies can be undertaken.

The authors acknowledge with gratitude the assistance and support of Dr Miriam G Wilson and the staff of the Division of Medical Genetics, Los Angeles County-University of Southern California Medical Center.

\section{Addendum}

The mother of case 5 , pregnant at the time the manuscript was submitted, has had a second affected infant.

\section{References}

1 Jeune M, Beraud C, Carron R. Dystrophie thoracique asphyxiante de caractère familial. Arch Fr Pediatr 1955;12:886-91.

2 Jeune M, Carron R, Beraud C, Loaec Y. Polychondrodystrophy avec blockage thoracique d'evolution fatale. Pediatrie 1971:9: $390-2$.

${ }^{3}$ Midulla M, Moschini L, Paolone G, Marino P. Distrofia toracica de Jeune. Minerva Pediatr 1971;23:19-29.

${ }^{4}$ Tahernia AC, Stamps P. 'Jeune syndrome' (asphyxiating thoracic dystrophy): report of a case, a review of the literature, and an editor's commentary. Clin Pediatr 1977;16:903-7.

5 Langer LO. Thoracic-pelvic-phalangeal dystrophy: asphyxiating thoracic dystrophy of the newborn, infantile thoracic dystrophy. Radiology 1968;91:477-56.

${ }^{6}$ Langer LO. The thoracic-pelvic-phalangeal dystrophy. Birth Defects 1969;5(4):55-64.

${ }^{7}$ Finegold MJ, Katzew H, Genieser NB, Becker MH. Lung structure in thoracic dystrophy. Am J Dis Child 1971;122:153-9.

${ }^{8}$ Burkle FM, Bravo AJ. Asphyxiating thoracic dystrophy: malformation of the newborn. Clin Pediatr 1969;8:165-70.

${ }^{9}$ Gruskin AB, Baluarte HJ, Cote ML, Elfenbein IB. The renal disease of thoracic asphyxiant dystrophy. Birth Defects 1974;10(4):44-50.

${ }^{10}$ Herdman RC, Langer LO. The thoracic asphyxiant dystrophy and renal disease. Am J Dis Child 1969;116:192-201.

$"$ Kohler E, Babbit DP. Dystrophic thoraces and infantile asphyxia. Radiology 1970;94:55-62.

12 Penido R, Carrell R, Chialastri AJ. Case review: asphyxiating thoracic dystrophy in a teenager. J Pediatr 1978;2:338-43.

13 Kozlowski K, Masel J. Asphyxiating thoracic dystrophy without respiratory disease: report of two cases of the latent form. Pediatr Radiol 1976;5:30-3.

14 Kaufmann HJ, Kirkpatrick JA. Jeune thoracic dysplasia - a spectrum of disorders? Birth Defects 1974;10(9):101-16.

15 Barnes ND, Hull D, Symons JS. Thoracic dystrophy. Am J Dis Child 1969;44:11-7.

${ }^{16}$ Carbonini M, Cicchetti F, Ferruti M, Longhi A. Distrofia toracica asfissiante (sindrome di Jeune): aspetti clinici e medicolegale. Minerva Ginecol 1969;21:1223-36.
17 Edelson PJ, Spackman TJ, Belliveau RE, Mahoney MJ. A renal lesion in asphyxiating thoracic dysplasia. Birth Defects 1974;10(4):51-6.

${ }^{18}$ Neimann N, Manciaux M, Rauber G, Pernot C, Bretagne-deKersauson MC. Dystrophie thoracique asphyxiante du nourrison. Pediatrie 1963;18:387-97.

${ }^{14}$ Chaptal J, Jean R, Pages A, Dossa D, Lamarche M, Dumas A. Chondrodystrophie a predominance thoracique deux observations. Montpellier Med 1964;65:287-95.

20 Shokeir MHK. Houston CS, Awen CF. Asphyxiating thoracic dystrophy: association with renal disease and evidence for possible heterogeneous expression. J Med Genet 1971;8:107-12.

21 Razzi A, Rosso C, Durand P. Contributo anatomopatologico alla distrofia toracica asfissiante del lattante (malattia de Jeune) e conserazione sull' utilita tcrapcutic dell' intervento chirurgico sulle costoc. Minerva Pediatr 1965;17:1823-7.

${ }^{22}$ Yang SS, Heidelberger KP, Brough AJ. Corbett DP. Bernstein J. Lethal short-limbed chondrodysplasia in carly infancy. Perspect Pediatr Pathol 1976;3:1-40.

${ }^{2.3}$ Zizka J, Rehulova E. Jutternova V. Balicck P. Asfyktizujici torakalni dystrofie. Cesk Pediatr 1979:34:98-9.

${ }^{24}$ Slomic A. Bouliane R. Maturation osscuse dans la dysplasic thoracique asphyxiante et la nanisme diastrophique a la period neo-natale. J Radiol Electrol 1977:58:17-20.

25 Phillips SJ, Magsamen BF, Punnett HH, Kistenmacher ML, Campo RD. Fine structure in skeletal dysplasia as seen in pseudoachrondroplastic spondylocpiphyscal dysplasia and asphyxiating thoracic dystrophy. Birth Defects 1974;10(12):314 26.

26 Sacrez R. Levy JM. Halb A. et al. La dystrophic thoracique asphyxiante. Pediatrie 1966:21:631-43.

27 Morgan AD. Cor pulmonale in children: review and etiologic classification. Am Heart J 1967:73:550-62.

${ }^{2 x}$ Friedman JM, Kaplan HG, Hall JG. The Jeune syndrome (asphyxiating thoracic dystrophy) in an adult. Am J Med 1975;57:857-62.

29 Gordecv VV, Ananeva AP. Frolova MA. Sindrom Jcunc. Pediatriia 1980;7:63.

3) Landing BH, Wells T, Claircaux AE. Morphometric analysis of liver lesions in cystic discase of childhood. Hum Pathol 1980;11(suppl):549-60.

${ }^{31}$ Pirnar T, Neuhauser EBD. Asphyxiating thoracic dystrophy of the newborn. AJR 1966:98:358-64.

${ }^{32}$ Bernstein J, Brough AJ, McAdams AJ. The renal lesion in syndromes of multiple congenital malformations: Jeunc asphyxiating thoracic dystrophy, tuberous sclerosis, Meckel syndrome. Birth Defects 1974:10(4):35-43.

${ }^{33}$ Shah KJ. Renal lesions in Jcunc's syndrome. Br J Radiol 1980:53:432-6.

${ }^{34}$ Robins DG, French TA, Chakera TMH. Juvenile nephronophthsis associated with skeletal abnormalities and hepatic fibrosis. Arch Dis Child 1976;51:799-801.

${ }^{35}$ Kozlowski K, Masel J, Morris L, Kunze D. Neonatal death dwarfism. ROEFO 1978;129:626-33.

${ }^{36}$ Karjoo M. Koop CE, Cornfeld D. Holtzapple PG. Pancreatic exocrine enzyme deficiency associated with asphyxiating thoracic dystrophy. Arch Dis Child 1973;48:143-6.

37 Hanissian AS, Riggs WW. Thomas DA. Infantile thoracic dystrophy-a variant of Ellis-van Creveld syndrome. J Pediatr 1967;71:855-64.

36 Spranger J, Langer LO, Weller MH, Hermann J. Short rib-polydactyly syndromes and related conditions. Birth Defects $1974 ; 10(9): 117-23$.

${ }^{39}$ Kaufmann HJ.'New' skeletal dysplasias in the newborn: new x-ray findings. Birth Defects 1974;10(12):1-9.

4) Richardson MM, Beaudet AL, Wagner ML, Malini S, Rosenberg HS, Lucci JA. Prenatal diagnosis of recurrence of Saldino-Noonan dwarfism. J Pediatr 1977;91:467-71. 
${ }^{+1}$ Wendler VH. Rossipal E. Dic familiare asphyxierende Thoraxdystrophic (Morbus Jeunc). Arch Kinderheilkd 1969;179: 171-82.

42 Phillips CI, Stokoe NL, Bartholomew RS. Asphyxiating thoracic dystrophy (Jcune's disease) with retinal aplasia: a sibship of two. J Pediatr Ophthalmol Strabimus 1979;16:279-83.

${ }_{43}$ Szabo L. Takacs I. Jeune-syndroma (thoraco-pelvo-phalangealis dystrophia, asphyxiating thoracic dystrophy). Orv Hetil 1980:121:2699-704.

44 Centa A, Rasore-Quartino A. Su di nuovo caso di distrofia toracica asfissiante (malattia di Jeune): consierazioni cliniche, radiologiche, e genetiche. Minerva Pediatr 1967;19:1924-8.
45 Charminade F, Stanescu V, Stancscu R, Maroteaux P. Linkproteins and non-collagenous proteins from normal and chondrodystrophic cartilages. Eur J Pediatr 1979;131:237-45.

${ }^{46}$ Ludwig J. Current methods of autopsy practice. Philadelphia: Saunders, 1979:676,8

Correspondence and requests for reprints to Dr Susan Beckwitt Turkel, Department of Pathology, University of Southern California, School of Medicine, 2025 Zonal Avenue, Los Angeles, California 90033, USA. 